Article

\title{
Improving Irrigated Lowland Rice Water Use Efficiency under Saturated Soil Culture for Adoption in Tropical Climate Conditions
}

\author{
Aimé Sévérin Kima ${ }^{1}$, Wen Guey Chung ${ }^{2}$ and Yu-Min Wang ${ }^{2, *}$
}

1 Department of Tropical Agriculture and International Cooperation, National Pintung University of Science and Technology, Pingtung 91201, Taiwan; E-Mail: aimeseverinkima@yahoo.fr

2 Department of Civil Engineering, National Pintung University of Science and Technology, Pingtung 91201, Taiwan; E-Mail: wenguey@mail.npust.edu.tw

* Author to whom the correspondence should be addressed; E-Mail: wangym@mail.npust.edu.tw; Tel.: +886-8-770-3202 (ext. 7203); Fax: +886-8-774-0122.

Received: 8 May 2014; in revised form: 15 August 2014 / Accepted: 4 September 2014 /

Published: 25 September 2014

\begin{abstract}
Saturated soil culture is one of the water saving techniques that can improve water productivity. However, it is either less implemented or adopted because it consumes more time and energy. Therefore, an experiment was conducted to determine the effective water depth that can keep soil moisture close to saturation for a commonly practiced irrigation interval, combined with a rainfall pattern for increasing water productivity. The design was a randomized complete block with three replications and four water treatments representing 120\% (T120), 180\% (T180), 240\% (T240), and 300\% (T300) of soil saturation or the application of 2, 3, 4 and $5 \mathrm{~cm}$ water depth. The results showed that the application of $3 \mathrm{~cm}$ was the effective depth. It decreased plant height, tiller number, chlorophyll content, and panicle number per hill by $12.37 \%, 20.84 \%, 7.59 \%$, and $70.98 \%$, respectively. The decrease of these parameters is followed by total recovery due to effective rainfall contribution, which led to low yield sacrifice ( $6 \%$ of reduction) and $40 \%$ of water saving. We argue that weekly application of a $3 \mathrm{~cm}$ water depth and matching crop needed-water period with the onset of rainfall may be implemented and recommended as suitable saturated soil culture practice for rice production in high water demand conditions.
\end{abstract}

Keywords: saturated soil culture; lowland rice yield; water productivity; tropical climate 


\section{Introduction}

The high competition for water is putting a great deal of strain on the availability of irrigation water, especially for high water intensive crops, such as lowland rice, and the situation is exacerbated by climate change. In the past ten years, growth in rice yield has dropped below $1 \%$ per year worldwide, while an increase of rice yield, to more than $1.2 \%$ per year, is required to meet the growing demand for food [1]. Increased rice supply is constrained by the lack of sufficient water availability [2] induced by increasing demands of other sectors. In such circumstances, the great challenge for agriculture is to produce more rice with less water if food security is to be maintained, thus, irrigation water use efficiency should play a greater role in meeting future rice demands. Traore et al. [3] indicated the criticality of water use efficiency in rice production. According to Wang et al. [4], the only solution for worldwide water shortage problem is to make efficient use of agricultural water.

Innovative water saving technologies, such as saturated soil culture (SSC), which require less water, especially for irrigated lowland rice production, has been developed, tested, and recommended to replace traditional continuous flooding in coping with water scarcity for rice sustainability. Previous studies [5-7] revealed the effectiveness of soil saturation culture compared with continuous flooding in terms of yields and water productivity. Yields may decline under this practice, but water saving and water productivity increases. SSC can drastically cut down the unproductive water outflows and increase water productivity [8]. Tuong and Bhuiyan [9] mentioned that saturated soil culture can diminish water losses, reduce water use, and maintain or increase production for rice-based systems. Lampayan and Bouman [10] showed that, compared with the heavy investments needed to develop new water resources, the adoption of water-saving technologies by farmers is low-cost and has great potential to save water.

These previous studies focused on the applied amount of irrigation water without much attention in matching rain occurrence with the crop high needed water stage. Basically, the main target was to keep daily soil moisture at saturation level and irrigation frequently stopped when rain occurred. However, high water productivity cannot be achieved in irrigation regardless of rainfall occurrence opportunities at specific growth stage, especially for an area like Taiwan where there is high rain variability. Taiwan is located in a region dominated by two prevailing typhoon tracks [11] and the frequency of rainfall shows a decreasing trend for lighter rain and an increasing trend for heavier rain. Typhoon rainfall shows a significant increase for all intensities, while non-typhoon rainfall exhibits a general trend of decreasing, particularly for lighter rain; for both typhoon and non-typhoon rainfall extremes, become more intense [12]. Chen et al. [13] mentioned that the climate diversity over Taiwan is most evident in terms of striking spatial variations in rainfall.

Water productivity can be increased when taking advantages of both irrigated and rainfed agriculture. Decreasing irrigation water supply and taking full advantages of rainwater during high needed water period may lead to high water productivity for both irrigation and rain water, consequently cutting down irrigation costs.

Moreover, keeping daily soil moisture near or at saturation level particularly at low crop water requirement stages may decrease water use efficiency since the entire available water will not be consumed. Additionally, daily irrigation application requires more time and leads to high energy consumption that may increase input, reduce farm profitability, and may affect negatively the adoption of this practice. Irrigated production costs vary according to different irrigation systems. For systems 
that require water pumping, water cost, and high labor, saving water gives advantage for reducing particularly energy consumption, and globally inputs; that leads to farm output increase.

Therefore, this study aimed to find out the effective amount of water that may keep soil moisture close to saturation, for an irrigation interval commonly used by farmers (seven days), and improve water productivity with low yield sacrifice under Taiwan rainfall variability conditions. That will help to ease the application of SSC, and give opportunities to farmers to overcome time consumption, save energy and water, reduce production costs, and increase water efficiency for sustainable rice production.

\section{Materials and Methods}

\subsection{Site Description and Experimental Design}

The experiment was carried out at National Pingtung University of Science and Technology irrigation field $\left(22.39^{\circ} \mathrm{N}, 34.95^{\circ} \mathrm{E}\right.$, and $71 \mathrm{~m}$ above sea level) from 5 January to 12 June, 2013. Based on the rainfall regimes, the production period corresponded to winter (December-February), spring transition (March and April), and the early summer rainy season or mei-yu season (mid-May to mid-June) as categorized by Wang and Chao [14]. The soil type was loamy (27\% of sand and $24 \%$ of clay) with wilting point $15 \%$ volume; field capacity $30.5 \%$ volume; saturation $42.9 \%$ volume; bulk density 1.40 $\mathrm{g} / \mathrm{cm}^{3}$; matric potential $11.09 \mathrm{bar}$; and hydraulic conductivity $57 \mathrm{~mm} / \mathrm{h}$. The experimental design was randomized complete blocks with three replications and four irrigation water treatments (T120, T180, T240 and T300). Irrigation amounts were determined based on the soil saturation level at a $60 \mathrm{~cm}$ depth, and were 120\% (T120), 180\% (T180), 240\% (T240) and 300\% (T300). The applied amounts of water represented a 2, 3, 4, and $5 \mathrm{~cm}$ depth above soil surface for T120, T180, T240 and T300, respectively.

\subsection{Nursery Establishment}

Dry-bed nursery was set up and the tillage was done at $30 \mathrm{~cm}$ depth on 5 January. Four nurseries were established, each with a total area of $1.8 \mathrm{~m}^{2}$ and $0.15 \mathrm{~m}$ height. Fertilizer with $12: 18: 12$ ratio of $\mathrm{N}: \mathrm{P}_{2} \mathrm{O}_{5}: \mathrm{K}_{2} \mathrm{O}$ was applied at a rate of $270 \mathrm{~kg} \cdot \mathrm{ha}^{-1}$. After fertilizer application, $50 \mathrm{~kg} \cdot \mathrm{ha}^{-1}$ of seeds was sown in lines at a $10 \mathrm{~cm}$ spacing and nurseries were watered until soil saturation. Two extra nurseries were also established to replace dead plantlets. Irrigation water supply was kept at 4 days interval until the emergence of seedlings. After the seedlings emerged, irrigation interval was shifted to 3 days with the application of the same amount of water until transplanting.

\subsection{Land, Crop and Water Management}

Land preparation started two weeks before transplanting. Dry tillage was done at $0.3 \mathrm{~m}$ depth and bunds were made at $0.15 \mathrm{~m}$ height and well compacted. Each plot was $6 \mathrm{~m}$ long and $1 \mathrm{~m}$ wide, with a total area of $6 \mathrm{~m}^{2}$. Plots were manually levelled, soaked at soil saturation, and transplanting was done the same day (4 February). Thirty-day-old seedlings were manually transplanted at a density of three seedlings per hill at $25 \mathrm{~cm} \times 20 \mathrm{~cm}$ spacing. To ensure that nutrients were not limiting crop development, fertilizer NPK was broadcasted manually at the rate of $270 \mathrm{~kg} \cdot \mathrm{ha}^{-1}$ at basal, mid-tillering, and panicle initiation. Pests were intensively controlled by pesticides and weeds were manually removed twice a month. 
After transplanting, water treatments were immediately applied and irrigation interval was defined at 7 days, as commonly practiced by farmers. The required amount of water to reach the soil saturation was calculated using the equation below [15]:

$$
\mathrm{IR}_{\mathrm{sat}}=\mathrm{SW}_{\mathrm{sat}}-\mathrm{SW}_{\mathrm{wp}} \times \mathrm{D} \times \mathrm{A}
$$

where $\mathrm{IR}_{\text {sat }}$ is the amount of irrigation water (liter) at saturation level; $\mathrm{SW}_{\text {sat }}$ and $\mathrm{SW}_{\mathrm{wp}}$ stand for soil water content volume basis (\%) at saturation and wilting point, respectively; while D is root depth (cm) and $\mathrm{A}$ the area $\left(\mathrm{m}^{2}\right)$.

Basin irrigation system was used; water was applied through a horse pipe and the water amount was measured using tanks with known volume. The irrigation ended at the onset of summer rainy season (11 May) corresponding to the heading stage and crops were harvested on 12 June. However, from the panicle initiation to the end of the irrigation, irrigation was not applied when rain occurred during the irrigation day or a day before, but irrigation interval was kept at 7 days.

\subsection{Soil Moisture Analysis}

Soil moisture was monitored every 2 days from week 5 ( 8 March) after transplanting to heading. Soil samples were collected using an auger in three different locations per plot at $20 \mathrm{~cm}$ depth. Soil was immediately weighted and dry weight was obtained after oven drying at $105{ }^{\circ} \mathrm{C}$ for $24 \mathrm{~h}$. The soil moisture content per unit of volume was calculated using Equation (2):

$$
\mathrm{SW}=\frac{100 \times(\text { fresh weight }- \text { dry weight })}{\text { Dry weight }} \times \gamma \mathrm{s}
$$

where SW is the soil water content and $\gamma$ s stands for soil bulk density $\left(\mathrm{g} / \mathrm{cm}^{3}\right)$.

The water stress threshold at a $20-\mathrm{cm}$ depth was determined using the equation below derived from Allen et al. [16]:

$$
\mathrm{SW}_{\mathrm{ST}}=1000(1-\mathrm{p}) \mathrm{SW}_{\text {sat }} \times \mathrm{Z}_{\mathrm{r}}
$$

where SW depleted before moisture stress occurs and represents $20 \%$ of the saturation for rice; $\mathrm{Z}_{\mathrm{r}}$ is the samples collection depth (m).

\subsection{Sampling and Crop Parameters Measurement}

\subsubsection{Chlorophyll Content}

Chlorophyll meter (model SPAD-502, MINOLTA, Japan) was used to determine the leaves chlorophyll content. It provides a simple, quick, inexpensive, and nondestructive method [17]. It is an in vivo technique that does not require sample preparation [18]. For scientists and farmers with limited direct access to laboratory analysis, the chlorophyll meter is convenient $[19,20]$. It measures an index related to chlorophyll and allows accurate measurements of relative leaf chlorophyll content [21]. Good correlations have been found between the SAP-502 value and extractable leaves chlorophyll content in several species although specific calibration is always recommended $[22,23]$. 
At 45 days after transplanting, plots were divided into three parts (each part being $3 \mathrm{~m}^{2}$ ) and 5 hills were selected through the diagonals. Five uppermost fully expanded leaves were randomly selected from these sampled hills to analyze the variability of leaves chlorophyll amount treatments. In total, fifteen leaves were chosen per plot. A specific leaf area, located between $40 \%$ and $70 \%$ along the leaf length from the leaf base, was identified and three readings were done at three different points on this area. Analysis of leaves sampling patterns done by Chapman and Barreto [19] showed that at least four leaves per plot are needed, with several observations per leaf. Then, the average of these three readings represented the leaf chlorophyll content. Measurements were taken at mid-tillering, panicle initiation, and heading stages.

\subsubsection{Growth Parameters, Yield and Yield Components and Water Productivity Assessment}

At the early vegetative stage, one square meter quadrat was placed in the middle of each plot and plant growth parameters (height and tiller number) were measured from each of the 20 hills individually. Plant height was measured from the base to the tip of the highest leaf at panicle initiation (PI) and heading. Tillers were counted individually and the number was determined at both above-mentioned stages and at harvest.

For roots and biomass per hill assessment, six hills from each replicate were randomly selected outside the squares. At the active tillering, root sampling was completed after the total disappearance of irrigation water using an auger to remove soil along selected hills at $20 \mathrm{~cm}$ depth. A uniform soil volume $\left(1570 \mathrm{~cm}^{3}\right)$ was excavated; roots were carefully washed with tap water, cut from uprooted plants. Roots volume was measured by water displacement method of putting all the roots in a measuring cylinder and getting the displaced water volume [2]. The procedure was conducted cautiously to prevent root damages and losses. Rooting depth was obtained by direct manual measurements of tap root length using a ruler against a millimeter paper. Roots dry weight and dry biomass per hill were obtained after oven drying at $70{ }^{\circ} \mathrm{C}$ for $24 \mathrm{~h}$.

At harvest, yield components (panicle number per hill, panicle length and weight, grains number per panicle, grain weight per panicle, and filled grain per panicle) were obtained from plants within the squares. Panicles were cut at the base, separated from the straw, and the number was determined for each hill. Panicles were arranged into three homogeneous groups according to their size similarity; five panicles were then randomly picked from each group for length and weight measurements. The same sampled panicles were individually hand threshed and grains number per panicle was manually counted. Grains weight per panicle was obtained at a constant weight after oven drying at $70{ }^{\circ} \mathrm{C}$ for $72 \mathrm{~h}$. All plants in squares were harvested, excluding those in edges, for grain yield per unit of area $\left(\mathrm{t} \cdot \mathrm{ha}^{-1}\right)$ determination. Three samples of harvested grains were randomly picked from each replicate and the dry weight was determined at a constant weight after oven drying at $70{ }^{\circ} \mathrm{C}$ for $72 \mathrm{~h}$. Grain yield was then adjusted at the standard moisture content of $14 \%$. Five samples of 1000 grains were taken from the total grains production of each plot and weighted for 1000 grains weight determination. Filled spikelets from these samples were separated from unfilled spikelets using a seed blower for $2 \mathrm{~mm}$. The percentage of filled grain was calculated, mass basis, as the ratio of filled grains weight out of the total grains weight multiplied by 100 . Fifteen samples were considered per treatment. The dry biomass per hill from the harvested plants was determined after oven drying at $70{ }^{\circ} \mathrm{C}$ for $24 \mathrm{~h}$, and the total straw weight $\left(\mathrm{t} \cdot \mathrm{ha}^{-1}\right)$ 
was calculated accordingly. The harvest index (HI) was calculated as the ratio of total grain yield out of the total straw yield.

Rainfall, which occurred during the growth period, was effectively stored in the bunded plot, and water input was calculated as the sum of irrigation water amount and rainwater. The total water productivity (TWP), the irrigation water productivity (IWP), and rainwater productivity (RWP) were calculated according to Equations (4)-(6) [24]:

$$
\begin{gathered}
\mathrm{TWP}=\frac{\mathrm{Y}}{\mathrm{TWU}} \\
\mathrm{IWP}=\frac{\mathrm{Y}}{\mathrm{IWU}} \\
\mathrm{RWP}=\frac{\mathrm{Y}}{\mathrm{RW}}
\end{gathered}
$$

where TWP, IWP, and RWP are the total water (rain + irrigation), irrigation water, and rainwater productivity, respectively, expressed in $\mathrm{kg} \cdot \mathrm{m}^{-3}$; Y is the grain yield $\left(\mathrm{kg} \cdot \mathrm{ha}^{-1}\right)$; TWU, IWU, and RW are the total water, irrigation water, and rain water used, respectively, expressed in $\mathrm{m}^{3} \cdot \mathrm{ha}^{-1}$.

Grain production losses were calculated considering the yield in the highest water treatment as a reference, and "water savings impact" was defined as the grain production lost by saving one unit of irrigation water. "Water savings impact" was obtained by dividing the quantity of grain lost per hectare by the amount of irrigation water saved $\left(\mathrm{m}^{3} / \mathrm{ha}\right)$.

\subsection{Statistical Analysis}

The data were subjected to statistical analysis of variance technique using SPSS 18 software (IBM, Armonk, New York, United States). The significance of treatments effect was determined using F-test and means were separated through Turkey's test at 0.05 .

\section{Results}

\subsection{Production Environment}

Figure 1 presents daily rainfall, crop evapotranspiration (ETc), and rainfall distribution frequency. Weather data were recorded at National Pingtung University of Science and Technology meteorological station. ETc was obtained by multiplying ETo per adjusted Kc [16]. The calculation was done according to different growth stages.

During the production cycle, daily rainfall varied from 0 to $115 \mathrm{~mm}$ (registered in May). The most important rainfalls occurred in April, May, and June. Rain occurred frequently in June compared to other months (Figure 1A). Monthly rainfall values were $0.5 \mathrm{~mm}, 13.5 \mathrm{~mm}, 150 \mathrm{~mm}$ and $429 \mathrm{~mm}$ for February, March, April, and May, respectively. From 1 June to 12 June (harvest), $52.5 \mathrm{~mm}$ was recorded. According to growth stages, $10 \mathrm{~mm}$ of rain was registered during the vegetative stage (4 February 2013 to 30 March 2013), $215 \mathrm{~mm}$ from panicle initiation (30 March 2013) to heading (11 May 2013), and $420.5 \mathrm{~mm}$ from heading to harvest (12 June 2013). During the vegetative stage, rainfall represented $1.90 \%, 2.20 \%, 2.60 \%$ and $3.17 \%$ of the irrigation water applied in treatments T300, T240, T180 and 
T120, respectively. From panicle initiation to heading, it represented $41 \%, 47 \%, 56 \%$ and $68 \%$, respectively, of the same treatments.

Figure 1. Sketch of daily rainfall and crop evapotranspiration (A) and rainfall distribution (B) during the production cycle (January to June).

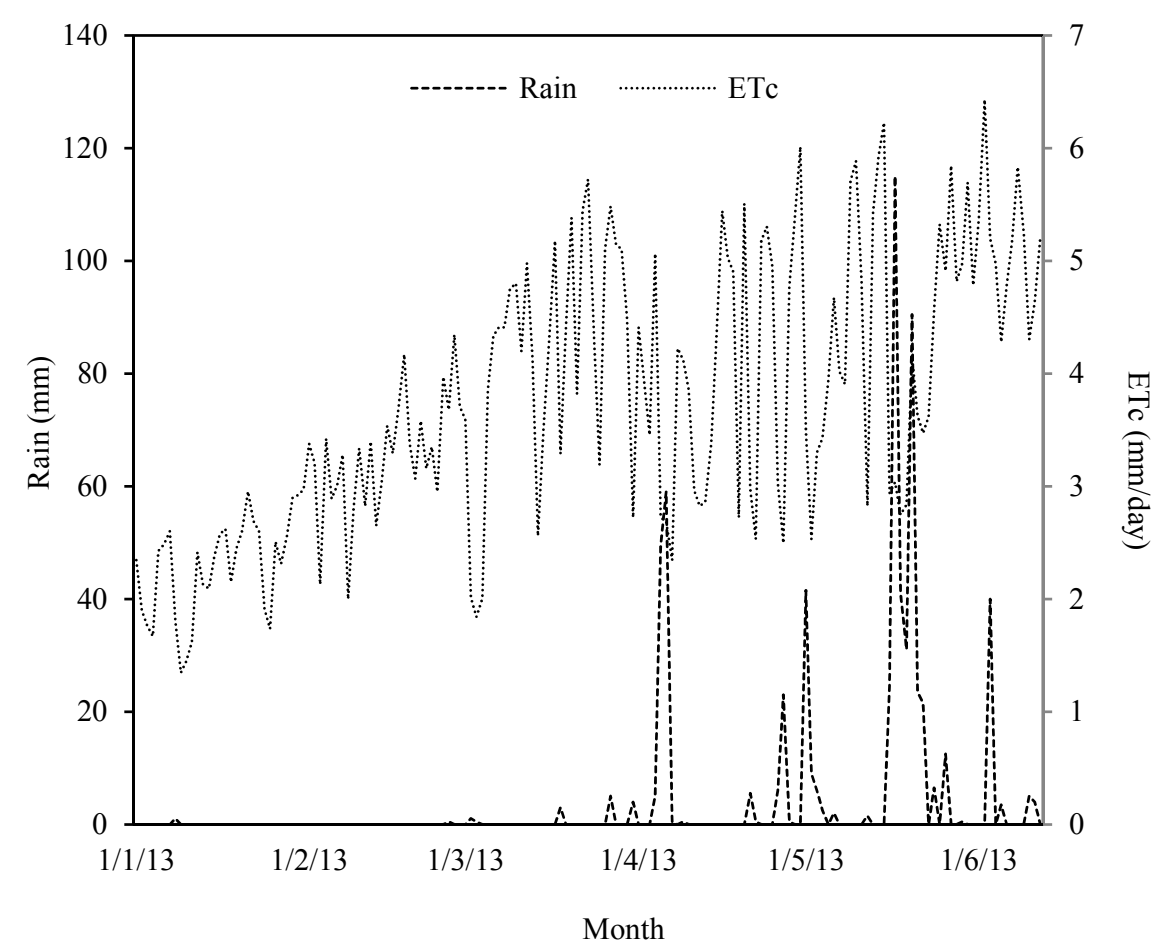

(A)

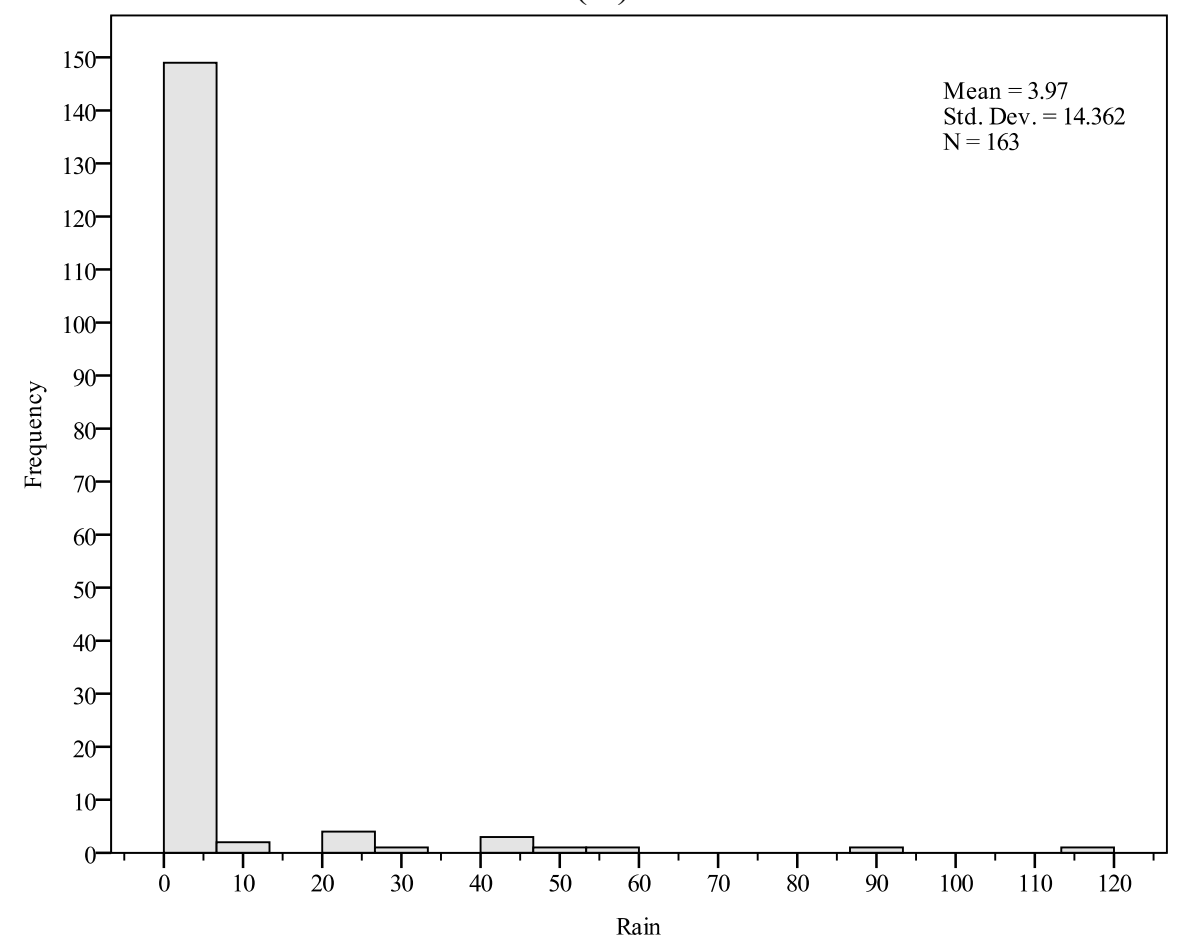

(B)

Along the production cycle, crop evapotranspiration varied from 1.35 to $6.43 \mathrm{~mm} / \mathrm{day}$. The lowest value of this parameter was observed in January, while the highest value was recorded in June. The trend of ETc showed that high crop water demands occurred on March, April, and June. These periods 
corresponded to active tillering, panicle initiation, reproductive, and late stages. From transplanting to panicle initiation (4 February 2013-30 March 2013), daily rainfall amount was lower than daily evapotranspiration, while from panicle initiation to harvest, rainfall was higher.

During the production period, the analysis of rainfall distribution showed slight variability (Standard Deviation $=14.362$ ) within days (Figure 1B). However, at the vegetative stage, plants grew almost exclusively under irrigation, while growth was subjected to both irrigation and rainfall from panicle initiation to heading. From heading to harvest plants were subjected to rainfall. The highest rainfall contribution occurred from heading to harvest. The total amount of water (irrigation and rain water) was higher from panicle initiation to heading than the others stages that led to well-watered soil conditions at this specific stage.

\subsection{Soil Moisture Content in Different Treatments}

Soil moisture content in different treatments is shown in Figure 2. During the vegetative stage (Figure 2A), soil moisture was significantly different among treatments, and varied according to the amounts of applied water. High moisture values were observed in the highest water treatment (T300) followed by T240 and T180, respectively, while the application of $2 \mathrm{~cm}$ water depth induced low values of soil water content. However, no significant difference was observed between T240 and T180. In all the treatments, soil water increased after irrigation and decreased gradually until the next irrigation. In T240, T180, and T120, crops were frequently under water stress, while T300 did not exhibit much water stress period. The stress was severe and the timing was relatively longer in T120 compare to T240 and T180, where the stress was slight. From panicle initiation to heading (Figure 2B), no difference was found among treatments, and soil moisture content values in all the treatments were above stress threshold. During this growth period, which corresponded to the spring and the early summer season, crops were not subjected to water stress.

\subsection{Rice Growth}

Root parameters and dry biomass were significantly affected by water regimes. Differences were observed among treatments (Figure 3). Roots were deeper (Figure 3A), and heavier (Figure 3B) in T300 compared to T240 and T180. At active tillering, water restriction decreased root length by $24.60 \%$ and $33.22 \%$ and root dry weight by $72.99 \%$ and $56.50 \%$ in T240 and T180, respectively. Similar results were observed in T120 and T300. For root volume (Figure 3C) and dry biomass per hill (Figure 3D), a decrease of $53.87 \%$ and $30.67 \%$, respectively, was observed only in T240. Water restriction in T120 and T180 at active tillering did not affect root growth and dry matter accumulation.

Plant height was affected by water treatments at both panicle initiation and heading, while the difference among treatments was observed only at panicle initiation for tiller number (Table 1). Height reduction rate was calculated by the ratio of height difference between each treatment and T300 over the height in T300 (considered T300 as the reference). At panicle initiation, water reduction decreased plant height by $19.78 \%, 12.37 \%$ and $11.4 \%$ in T240, T180 and T120, respectively. Similar approach was use for calculating tiller reduction, and it showed that tiller decreased by $20.84 \%$ in only T180. 
At heading, plant height was still affected by treatments and two groups were observed according to their similarity. Similar high values were observed in T300 and T240, and the low values were given by T180 and T120. However, for tiller number, no difference was observed at heading.

Water restrictions at the vegetative stage decreased both plant height and tiller number, but partial and total recovery were observed for these two growth parameters, respectively.

Figure 2. Soil moisture content in different treatments at the vegetative stage (A) and from panicle initiation to heading (B).

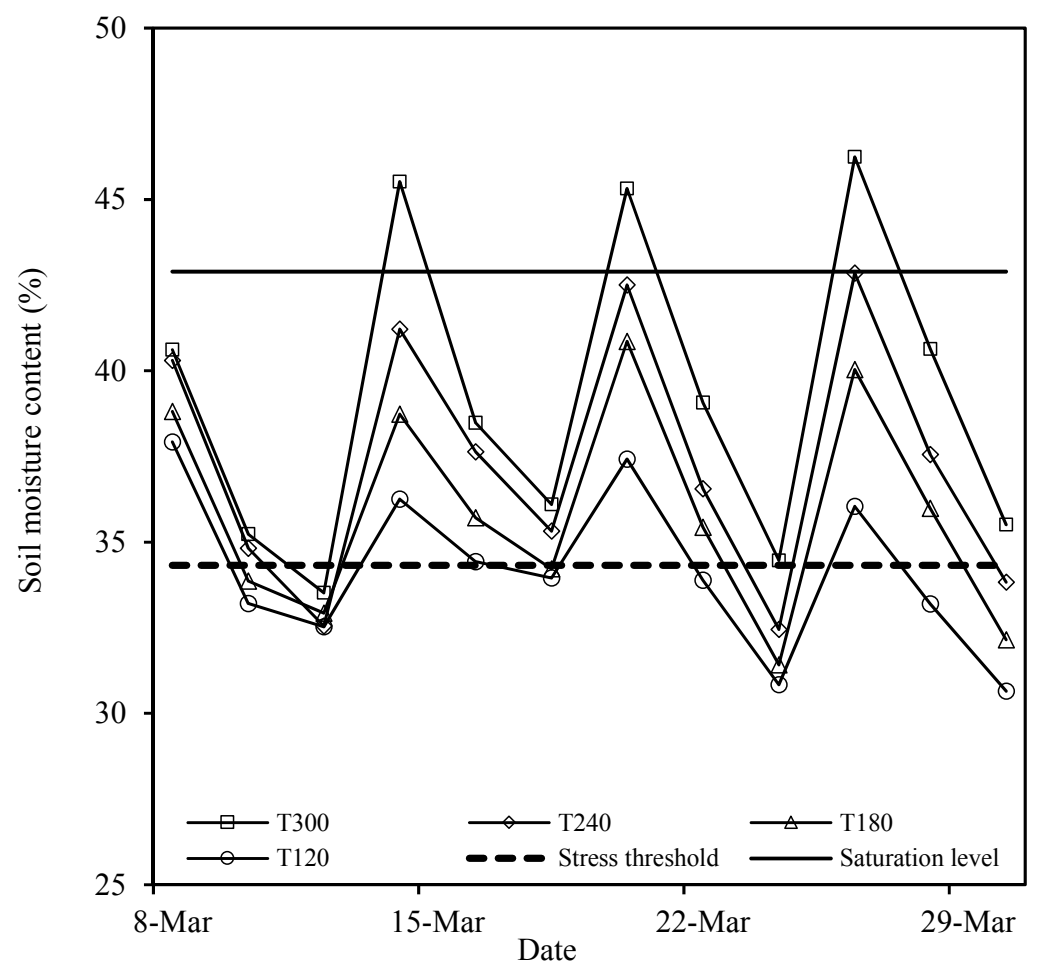

(A)

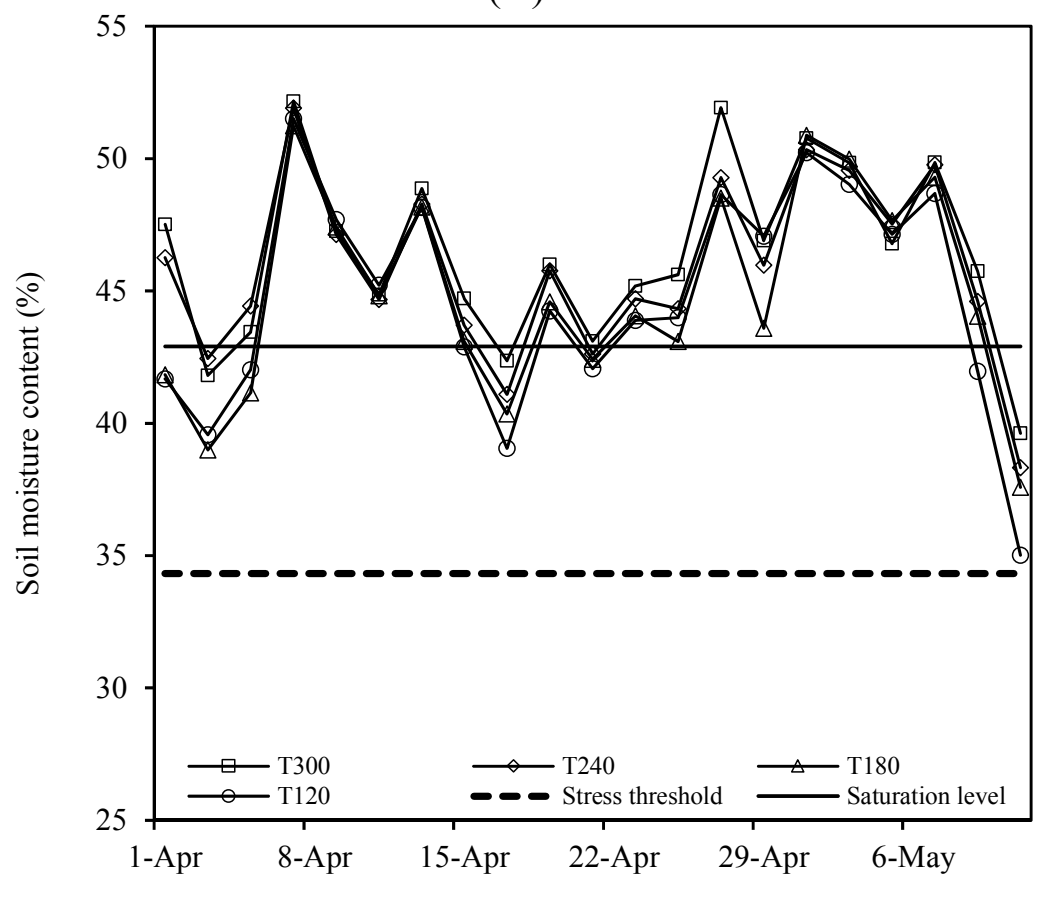

Date

(B) 
Figure 3. Effects of treatments on root length (A); dry weight $(\mathbf{B})$; volume $(\mathbf{C})$; and dry biomass (D) at active tillering.
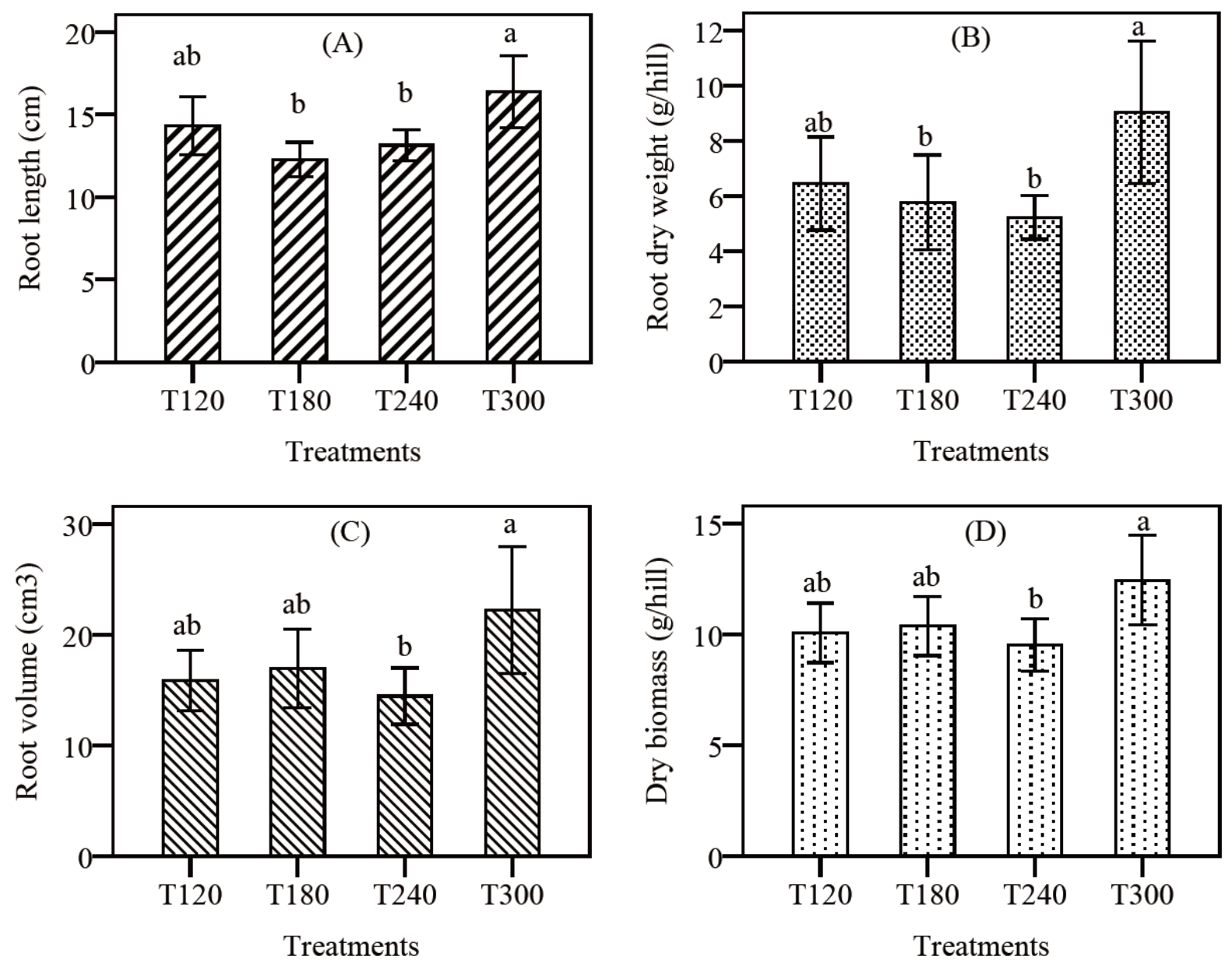

Table 1. Different water amount effects on plant height and tiller number.

\begin{tabular}{ccccc}
\hline \multirow{2}{*}{ Treatments } & \multicolumn{2}{c}{ Average plant height (cm) } & \multicolumn{2}{c}{ Average tiller number hill ${ }^{-1}$} \\
\cline { 2 - 5 } & Panicle initiation & Heading & Panicle initiation $^{\text {Heading }}$ \\
\hline T300 & $79.51^{\mathrm{a}}$ & $105.03^{\mathrm{a}}$ & $14.03^{\mathrm{a}}$ & 19.79 \\
$\mathrm{~T} 240$ & $66.38^{\mathrm{c}}$ & $105.41^{\mathrm{a}}$ & $12.57^{\mathrm{ab}}$ & 19.86 \\
$\mathrm{~T} 180$ & $70.76^{\mathrm{b}}$ & $101.56^{\mathrm{b}}$ & $11.61^{\mathrm{b}}$ & 18.43 \\
$\mathrm{~T} 120$ & $71.35^{\mathrm{b}}$ & $101.10^{\mathrm{b}}$ & $12.60^{\mathrm{ab}}$ & 19.19 \\
$\mathrm{p}$ & $* *$ & $* *$ & $* *$ & $\mathrm{~ns}$ \\
\hline
\end{tabular}

Notes: **: Means within columns not followed by the same letter are significantly different at $\mathrm{p}<0.01$ level by Turkey's test; ns: Not significantly different.

\subsection{Leaves Chlorophyll Content}

The chlorophyll content varied according to treatments and different growth stages (Figure 4). Although no significant difference was found between T300 and T240 at active tillering, Figure 4A shows that chlorophyll content was influenced by amount of water applied. Chlorophyll and decreased with a decrease of irrigation. Water decrease from 300 to 180 , and to $120 \%$ of soil saturation lowered leaves chlorophyll content by $7.59 \%$ and $6.17 \%$ in T180 and T120, respectively. However, at panicle initiation, the SPAD value of chlorophyll content was similar in T300 and T120 (Figure 4B), while no difference 
was observed among treatments at heading (Figure 4C). Chlorophyll content recovery was observed at panicle initiation in severe water stress treatment (T120), and in both T120 and T180 at the heading.

Figure 4. Effects water treatments on chlorophyll content: (A) at active tillering, (B) at panicle initiation and $(\mathbf{C})$ at heading.
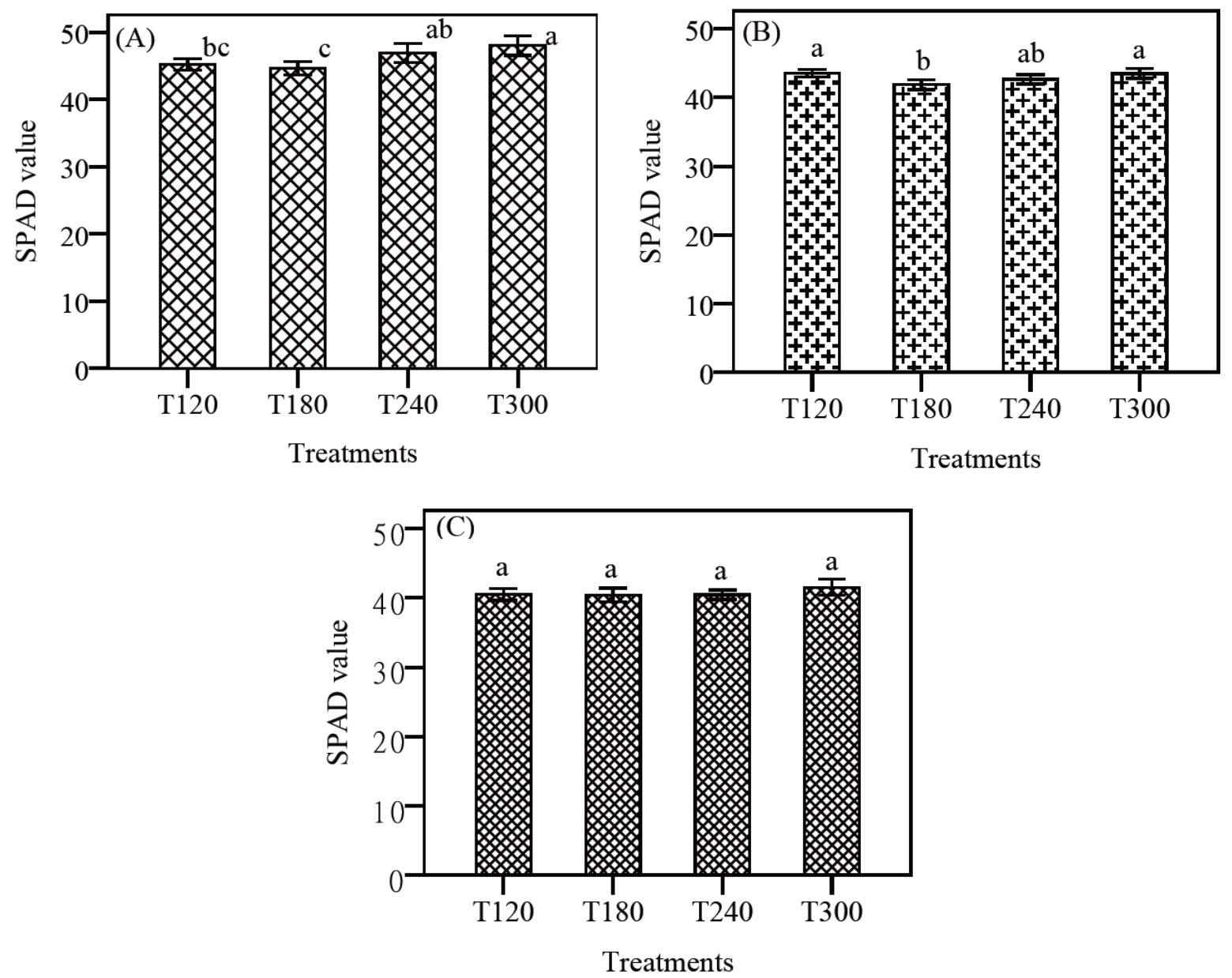

\subsection{Yield, Yield Components, and Water Use Efficiency}

Differences were observed in panicle numbers at heading, while, at harvest, panicles characteristics were similar in all treatments (Table 2). Panicle number per hill was 3 times higher in T300 than in T120, and decreased by $53.29 \%$ and $70.98 \%$ in T240 and T180, respectively.

Table 2. Water restriction effects on panicles characteristics.

\begin{tabular}{ccccc}
\hline \multirow{2}{*}{ Treatments } & \multicolumn{2}{c}{ Average panicle number hill $\mathbf{~}^{\mathbf{1}}$} & Average panicle length (cm) & Average panicle weight $(\mathbf{g})$ \\
\cline { 2 - 5 } & Heading & Harvest & Harvest & Harvest \\
\hline T300 & $9.78^{\mathrm{a}}$ & 20.20 & 20.20 & 1.29 \\
T240 & $6.38^{\mathrm{b}}$ & 19.80 & 19.8 & 1.21 \\
T180 & $5.72^{\mathrm{b}}$ & 18.89 & 18.88 & 1.33 \\
T120 & $3.25^{\mathrm{c}}$ & 20.49 & 20.48 & 1.22 \\
p & $* *$ & $\mathrm{~ns}$ & $\mathrm{~ns}$ & $\mathrm{~ns}$ \\
\hline
\end{tabular}

Notes: **: Means within columns not followed by the same letter are significantly different at $\mathrm{p}<0.01$ level by Turkey's test; ns: Not significantly different. 
One-thousand-grain weight and grain filling ratio were affected by treatments, while similar grain number per panicle and panicle grain weight were observed in all treatments (Table 3). T300 and T180 exhibited similar results, while 1000 -grain weight declined by $22.04 \%$ and $25.04 \%$ in $\mathrm{T} 240$ and T120, respectively.

Table 3. Effects of water reduction on grain production.

\begin{tabular}{ccccc}
\hline Treatments & $\begin{array}{c}\text { Average grain number } \\
\text { per panicle }\end{array}$ & Panicle grain weight (g) & Filling ratio & 1000-grain weight (g) $^{\text {100 }}$ \\
\hline T300 & 83.58 & 1.18 & $0.82^{\mathrm{a}}$ & $14.22^{\mathrm{a}}$ \\
$\mathrm{T} 240$ & 70.69 & 1.08 & $0.73^{\mathrm{b}}$ & $11.64^{\mathrm{b}}$ \\
$\mathrm{T} 180$ & 76.00 & 1.22 & $0.81^{\mathrm{a}}$ & $14.19^{\mathrm{a}}$ \\
$\mathrm{T} 120$ & 81.49 & 1.16 & $0.70^{\mathrm{b}}$ & $11.36^{\mathrm{b}}$ \\
p & $\mathrm{ns}$ & $\mathrm{ns}$ & $* *$ & $* *$ \\
\hline
\end{tabular}

Notes: **: Means within columns not followed by the same letter are significantly different at $\mathrm{p}<0.01$ level by Turkey's test; ns: Not significantly different.

Similar straw weight, grain yield and harvest index were observed in all treatments, while the lowest yield loss and yield reduction were given by $\mathrm{T}_{180}$ (Table 4).

Table 4. Water treatments effects on yield and harvest index.

\begin{tabular}{cccccc}
\hline Treatments & $\begin{array}{c}\text { Straw weight } \\
\text { (ton/ha) }\end{array}$ & $\begin{array}{c}\text { Grain yield } \\
\text { (ton/ha) }\end{array}$ & $\begin{array}{c}\text { Harvest index } \\
\text { (HI) }\end{array}$ & $\begin{array}{c}\text { Yield losses } \\
\text { (kg/ha) }\end{array}$ & $\begin{array}{c}\text { Yield reduction } \\
\text { (\%) }\end{array}$ \\
\hline T300 & 10.08 & 5.71 & 0.57 & - & - \\
T240 & 9.35 & 5.02 & 0.54 & 690 & 12.08 \\
T180 & 8.65 & 5.35 & 0.62 & 360 & 6.30 \\
T120 & 10.08 & 4.78 & 0.47 & 930 & 16.29 \\
p & ns & ns & ns & - & - \\
\hline
\end{tabular}

Note: ns: Not significantly different.

High rainwater productivity (0.88) was recorded in T300, while high total water productivity, irrigation water productivity, and high water savings were observed in T120 (Table 5). However, T180 exhibited the lowest production loss $\left(0.11 \mathrm{~kg} / \mathrm{m}^{3}\right)$ due to the saving of one unit of water.

Table 5. Effects of treatments on water use efficiency.

\begin{tabular}{|c|c|c|c|c|c|c|c|c|}
\hline Treatments & $\underset{\substack{\text { Rain } \\
\left(\mathbf{m}^{3} / \mathbf{h a}\right)}}{ }$ & $\begin{array}{c}\text { Irrigation } \\
\text { (m³/ha) }\end{array}$ & $\begin{array}{c}\text { TWP } \\
\left(\mathrm{kg} / \mathrm{m}^{3}\right)\end{array}$ & $\begin{array}{c}\text { RWP } \\
\left(\mathrm{kg} / \mathrm{m}^{3}\right)\end{array}$ & $\begin{array}{c}\text { IWP } \\
\left(\mathrm{kg} / \mathrm{m}^{3}\right)\end{array}$ & $\begin{array}{l}\text { Water } \\
\text { saving } \\
\left(\mathrm{m}^{3} / \mathrm{ha}\right)\end{array}$ & $\begin{array}{c}\text { Irrigation } \\
\text { water saving } \\
(\%) \\
\end{array}$ & $\begin{array}{c}\text { Water saving } \\
\text { impact } \\
\left(\mathrm{kg} / \mathrm{m}^{3}\right)\end{array}$ \\
\hline $\mathrm{T}_{300}$ & 6455 & 8500 & 0.38 & 0.88 & 0.67 & - & - & - \\
\hline $\mathrm{T}_{240}$ & 6455 & 6800 & 0.38 & 0.78 & 0.74 & 1700 & 20 & 0.41 \\
\hline $\mathrm{T}_{180}$ & 6455 & 5100 & 0.46 & 0.83 & 1.05 & 3400 & 40 & 0.11 \\
\hline $\mathrm{T}_{120}$ & 6455 & 3400 & 0.49 & 0.74 & 1.41 & 5100 & 60 & 0.18 \\
\hline
\end{tabular}




\section{Discussion}

The results showed that, although soil moisture was frequently located between water stress threshold and saturation at the vegetative stage, the reduction of irrigation water affected leaves chlorophyll content, plant height and tiller number. The decrease in chlorophyll content, height and tiller number is certainly due to water stress induced by irrigation water decrease. Under water stress, plants reduced evapotranspiration that led photosynthesis decrease with in turn induced chlorophyll decrease, height and tiller number reduction. Reddy et al. [25] showed that drought stress induced a decline in net photosynthesis and reduced growth rate. Water stress at the mid-tillering significantly decreased the number of panicle per hill [26]. However, it was seen in our study that severe water stress in the lowest treatment (T120) did not affect root development and dry biomass at active tillering, and chlorophyll content at the panicle initiation, and may be explained by the adaption mechanism developed by plants to overcome high water stress by extracting faster water in depth. Subjected to water stress, a plant develops its own adaptation mechanism through root development for water uptake in depth. Ascha et al. [27] reported that plant become adapted to water deficiency through the possession of a pronounced root system, which maximizes water capture and allows access to water at depth. The low values of root depth and root weight observed in T180 and T240 may be explained by the effects of hydraulic head pressure, which may have affected the infiltration rate. Chang et al. [28] highlighted that percolation increases when irrigation water increases. In these treatments, water depth on the soil surface may have led to an infiltration rate that did match in time with crop water uptake. The availability of the soil water in that case may have not reached a critical point for crop to develop deeper root system as an adaptation measure. Although the hydraulic head and water losses were not measured in our study, it is well known that infiltration rate is governed by the hydraulic head. Since transpiration and infiltration occur simultaneously, a critical hydraulic head pressure increases the infiltration rate and leads to low water uptake by plants. That induced low root volume and dry biomass, especially in T240. The amount of applied water depth $(4 \mathrm{~cm})$ in T240 may be the critical water depth that increased the gap between infiltration and water absorption. The low root development in T180 due less water uptake may have decreased the transpiration rate and induced low leaves chlorophyll content and dry biomass. In contrary, higher chlorophyll index observed in T240 compared with T180 may be due to high decrease of transpiration rate that reduced leaves water content and increased leaves chlorophyll concentration. Then, high chlorophyll index was recorded in T240 due to the fact that the chlorophyll index given by the chlorophyll meter is correlated to leaves chlorophyll concentration.

Growth decrease at panicle initiation was followed by partial and total recovery in height and tiller, respectively, at the heading. High effective rainfall recorded from panicle initiation to harvest increased soil moisture content, which rose frequently above saturation and led to well-watered conditions in all treatments, and allowed crop recovery. The partial and total recovery might be due to the ability of crop to extract water depending on the stress severity. Lilley and Fukai [29] showed that after the relief of water stress, crop growth rate depended on severity of stress, and the greater ability to extract water during the deficit increased growth rate during the recovery process. The recovery of plant growth would appear immediately through growing of new plant parts [30]. In spite of total recovery of tillers at heading, the decrease of panicle number per hill showed that effective tillers were affected by treatments. Irrigation reduction delayed heading rate, and decreased grain filling ratio and 1000-grain weight, 
although panicle number recovery was observed in all treatments at harvest. Davatgar et al. [31] showed that severe water stress at mid-tillering delayed flowering, and caused substantial yield losses by large percentage of unfilled grains. This finding has been confirmed by Pirdashti et al. [26] who pointed out that drought stress in the vegetative growth stage extended the number of days for flowering in different rice cultivars. However, T180 performed as well as T300 showing that, during the vegetative stage, the application of $3 \mathrm{~cm}$ water depth may have allowed an efficient water use by plants.

Finally, it was found that high rainwater productivity (0.88) was given by T300 followed by T180 (0.83), while high total water productivity (0.49) and irrigation productivity (1.41) were recorded in the lowest water treatment (T120) followed by T180 with 0.46 and 1.05 for TWP, and IWP, respectively. However, the lowest yield reduction (6.90\%) and the lowest grain production lost $(0.11 \mathrm{~kg})$ due to the saving of $1 \mathrm{~m}^{3}$ of water were given by T180, showing that the application of $180 \%$ of soil saturation led to optimal water productivity and water saving (40\%). This is in perfect agreement with Bouman and Tuong [6] who demonstrated that in Asia water savings under saturated soil conditions were on average $23 \%$ with yield reductions of only $6 \%$. Nguyen et al. [32] reported that, in Australia, SSC reduced water use by $16 \%-28 \%$ and improve water use efficiency by up to $20 \%$. Reducing irrigation water by applying a $3 \mathrm{~cm}$ water depth during the vegetative stage and matching crops high needed-water period with the onset of rain led to more effective use of early season rainfall that achieved high irrigation productivity with less yield expenses.

\section{Conclusions}

Water reductions at the vegetative stage delayed plant growth and affected grain filling rate and 1000-grain weight, but the recovery process induced by effective rainfall contribution was such that grain yield was not affected. By applying a $5 \mathrm{~cm}$ water depth from transplanting to heading, rainwater productivity increased, but induced low irrigation water productivity. Since rain water use does not require any cost, the use of high amount of irrigation water during the dry season appeared costly and non-beneficial. The experiment was carried out during a short period, which may appear as a limitation. However, the results showed that in water scarcity context, applying $180 \%$ of soil saturation water seems suitable for increasing both rice production and irrigation water productivity in tropical climate conditions. We argue that, rather than daily application of small amount of water, saturated soil culture practice can be adopted in specific agro climatic zone by adjusting the irrigation water depth according to the irrigation intervals. Weekly application of a $3 \mathrm{~cm}$ water depth above soil surface can be recommended to farmers as an alternative to save irrigation water, time, energy, and increase outputs. This approach may probably replace the conventional soil saturation practice that is difficult to be implemented practically, and can be adopted in high water demand areas and where water resource is limited. The rainfall variability was found slight and the approach may be suitable for the study area. The experiment will be replicated in order to capture long-term impact of rainfall variability on yields for promoting sustainable water management strategy. In addition, hydraulic head pressure and the hydraulic conductivity will be analyzed to highlight the effect of different water depths on infiltration rate, which may have affected water uptake, growth, and yields in different treatments. In addition, other water depths $(6,7$ and $8 \mathrm{~cm}$ for example) will be tested and linked to hydraulic head pressure to better understand the real effects of water depths variation on crop performance. 


\section{Acknowledgments}

The authors would like to thank Taiwan's International Cooperation and Development Fund (ICDF) for their supports during the implementation of this study. Acknowledgments also go to Taiwan National Science Council (NSC) for funding this research under the grant 102-2221-E-020-028; without their supports this study would not be possible.

\section{Author Contributions}

Aimé Sévérin Kima initiated the study and conducted the experiment in the field. He is also the one who proposed the first draft of the manuscript and finalized it after others authors suggestions.

When Guey Chung helped to identify relevant parameters for the study. He made many comments on the first draft of the manuscript and suggested statistical analysis.

Yu-Min Wang is the advisor of the first author. He helped to finalize the study proposal, and followed the work during the experiment period. He also provided all the input for the study.

\section{Conflicts of interest}

The authors declare no conflict of interest.

\section{References}

1. Normile, D. Reinventing rice to feed the world. Science 2008, 321, 330-333.

2. Ndiiri, J.A.; Mati, B.M.; Home, P.G.; Odongo, B.; Uphoff, N. Comparison of water savings of paddy rice under System of Rice Intensification (SRI) growing rice in Mwea, Kenya. Int. J. Curr. Res. Rev. 2012, 4, 63-73.

3. Traore, S.; Wang, Y.M.; Kerh, T. Artificial neural network for modeling reference evapotranspiration complex process in Sudano-Sahelian zone. Agric. Water Manag. 2010, 97, 707-714.

4. Wang, Y.M.; Namaona, W.; Traore, S.; Zhang, Z.C. Seasonal temperature-based models for evapotranspiration estimation under semi-arid conditions of Malawi. Afr. J. Agric. Res. 2009, 4, 878-886.

5. Thompson, J.A. Methods for increasing rice water use efficiency. In Rice Water Use Efficiency Workshop Proceedings; Humphreys, E., Ed. Cooperative Research Center for Sustainable Rice Production: Leeton, New South Wales, Australia, 1999; pp. 55-57.

6. Bouman, B.A.M.; Tuong, T.P. Field water management to save water and increase its productivity in irrigated lowland rice. Agric. Water Manag. 2001, 49, 11-30.

7. Tabbal, D.F.; Bouman, B.A.M.; Bhuiyan, S.I.; Sibayan, E.B.; Sattar, M.A. On-farm strategies for reducing water input in irrigated rice: Case studies in the Philippines. Agric. Water Manag. 2002, $56,93-112$.

8. Tuong, T.P.; Bouman, B.A.M. Rice production in water-scare environments. In Water Productivity in Agriculture: Limits and Opportunities for Improvement; Kijne. J.W., Barker, R., Molden, D.J., Eds.; CAB International: Oxford, UK, 2003; pp. 53-67.

9. Tuong, T.P.; Bhuiyan, S.I. Increasing water-use efficiency in rice production: Farm-Level perspectives. Agric. Water Manag. 1999, 40, 117-122. 
10. Lampayan, R.M.; Bouman, B.A.M. Management strategies for saving water and increase its productivity in lowland rice-based ecosystems. In Proceedings of the First Asia-Europe Workshop on Sustainable Resource Management and Policy Options for Rice Ecosystems, Hangzhou, Zhejiang, China, 11-14 May 2005.

11. Tu, J.Y.; Chou, C.; Chu, P.S. The abrupt shift of typhoon activity in the vicinity of Taiwan and its association with western North Pacific-East Asian climate change. J. Clim. 2009, 22, 3617-3628.

12. Tu, J.Y.; Chou, C. Changes in precipitation frequency and intensity in the vicinity of Taiwan: typhoon versus non-typhoon events. Environ. Res. Lett. 2013, 8, 1-7.

13. Chen, C.S.; Chen, Y.L. The rainfall characteristics of Taiwan. Mon. Weather Rev. 2003, 131, 1323-1341.

14. Wang, S.T.; Chao, Y.K. Natural season of the weather in the Taiwan area. Atmos. Sci. 1984, 11, 101-120.

15. Ekren, S.; Sonmez, C.; Ozcakal, E.; Kukul Kurttas, Y.S.; Bayram, E.; Gurgulu, H. The effects of different irrigation water levels on yield and quality characteristics of purple basil (Ocimum basilicium L.). Agric. Water Manag. 2012, 109, 155-161.

16. Allen, R.G.; Pereira, L.S.; Raes, D.; Smith, M. Crop Evapotranspiration, Guidelines for Computing Water Requirements; Food and Agriculture Organization of United Nations: Rome, Italy, 1998.

17. Peng, S.; García, F.V.; Laza, R.C.; Cassman K.G. Adjustment for specific leaf weight improves chlorophyll meter's estimate of rice leaf nitrogen concentration. Agron. J. 1993, 85, 987-990.

18. Monje, O.A.; Bugbee, B. Inherent limitations of nondestructive chlorophyll meters: a comparison of two types of meters. HortScience 1992, 27, 69-71.

19. Chapman, S.C.; Barreto, H.J. Using a chlorophyll meter to estimate specific leaf nitrogen of tropical maize during the vegetative growth. Agron. J. 1997, 89, 557-562.

20. Liu, Z.A.; Yang, J.P.; Yang, Z.C. Using a chlorophyll meter to estimate tea leaf chlorophyll and nitrogen contents. J. Soil Sci. Plant Nutr. 2012, 12, 339-348.

21. Marenco, R.A.; Antezana-Vera, S.A.; Nascimento H.C.S. Relationship between specific leaf area, leaf thickness, leaf water content and SPAD-502 readings in six Amazonian tree species. Photosynthetica 2009, 47, 184-190.

22. Markwell, J.; Osterman, J.C.; Mitchell, J.L. Calibration of the Minolta SPAD-502 leaf chlorophyll meter. Photosynth. Res.1987, 46, 467-472.

23. Uddling, J.; Geland-Alfredsson, J.; Piikki, K. Evaluating the relationship between leaf chlorophyll concentration and SPAD-502 chlorophyll meter readings. Photosynth. Res. 2007, 91, 37-46.

24. Pereira, L.S.; Cordery, I.; Iacovides, I. Improved indicators of water use performance and productivity for sustainable water conservation and saving. Agric. Water Manag. 2012, 108, 39-51.

25. Reddy, A.R.; Chaitanya, K.V.; Vivekanandan, M. Drought-induced responses of photosynthesis and antioxidant metabolism in higher plants. J. Plant Physiol. 2004, 161, 1189-1202.

26. Pirdashti, H.; Sarvestani Z.T.; Bahmanyar, M.A. Comparison of physiological responses among four contrast rice cultivars under drought stress conditions. World Acad. Sci. Eng. Technol. 2009, 25, 52-53.

27. Ascha, F.; Dingkuhn M.; Sow, A.; Audebert, A. Drought-induced changes in rooting patterns and assimilate partitioning between root and shoot in upland rice. Field Crop. Res. 2005, 93, 223-236. 
28. Chang, Y.C.; Kan, C.E.; Lin, G.F.; Chiu, C.L.; Lee, Y.C. Potential benefits of increased application of water to paddy fields in Taiwan. Hydrol. Process. 2001, 15, 1515-1524.

29. Lilley, J.M.; Fukai, S. Effect of timing and severity of water deficit on four diverse rice cultivars III. Phenological development, crop growth and grain yield. Field Crop. Res. 1994, 37, 225-234.

30. Xu, Z.; Zhou, G.; Shimizu, H. Plant responses to drought and rewatering. Plant Signal. Behav. 2010, 5, 649-654.

31. Davatgar, N.; Neishabouri, M.R.; Sepaskhah, A.R.; Soltani, A. Physiological and morphological responses of rice (Oryza sativa L.) to varying water stress management strategies. Int. J. Plant Prod. 2009, 3, 19-32.

32. Nguyen, H.T.; Fisher, K.S.; Fukai, S. Physiological responses to various water saving systems in rice. Field Crop. Res. 2009, 112, 189-198.

(C) 2014 by the authors; licensee MDPI, Basel, Switzerland. This article is an open access article distributed under the terms and conditions of the Creative Commons Attribution license (http://creativecommons.org/licenses/by/3.0/). 